\title{
Identification of letters in words and of single letters with pre- and postknowledge vs. postknowledge of the alternatives
}

\author{
DANIEL HOLENDER \\ Département de Psychobiologie Expérimentale, C.N.R.S., Marseille, France
}

\begin{abstract}
Two experiments were conducted to test how the "word letter phenomenon" (WLP)-a letter is better identified when embedded in a word than when presented alone-is affected by prior knowledge of the alternatives in a forced choice paradigm with tachistoscopic exposures. In Experiment 1, one group of subjects, who were given knowledge of the alternatives after the display, showed the usual WLP. The WLP was eliminated in a second group of subjects who were given knowledge of the alternatives both before and after the display. In Experiment 2, the same subjects were either precued or not precued on alternating trials of each block. It appeared that the WLP suppression with precuing resulted from a decrease in word performance whereas letter performance was unaffected by precuing. It is suggested that precuing exerts a detrimental effect, because, instead of attending to the word as a whole, subjects search for where in the word the forced choice would be plausible.
\end{abstract}

Reicher (1969) has reported a word superiority effect with tachistoscopic exposures which, following the terminology proposed by Johnston and McClelland (1973), consists of a "word apprehension effect" (WAE) and a "word letter phenomenon" (WLP). The WAE refers to the fact that letters are better recognized when embedded within words than when embedded within strings of unrelated letters. The WLP, which is the main topic of this paper, denotes a better recognition of letters embedded in words relative to letters presented alone.

Both effects were originally obtained when subjects were presented with a sequence of displays that randomly comprised either a four-letter word, a string of four unrelated letters, or a single letter. The display was immediately followed by a pattern mask and the subject had to choose which of two alternative letters was the one presented in the display. The position of the target in the display was signaled by the location of the alternative letters above or below the mask and by underscores filling the nontarget positions. The alternatives were chosen so that both the target and its distractor would form a word when a word was presented and both would form a nonword when a nonword was presented. This was

Part of this work was performed while the author was still at the Laboratoire de Psychologie expérimentale at the Université Libre de Bruxelles. The author was supported by the Belgian "Fonds de la Recherche fondamentale collective" under Contract No. 10.152. I am grateful to Dr. Paul Bertelson for his helpful comments on the manuscript. Thanks are due to Luz Cary, Claire Kagan, Josiane Lechat, and Philippe Mousty for assistance in data collection. The author's address: C.N.R.S. INP 3; 31, Chemin Joseph Aiguier, 13274 Marseille Cedex 2, France. assumed by Reicher (1969) to rule out the possibility that the subject uses redundant information from the word context to improve his performance by guessing when he imperfectly perceived the target.

The above description constitutes the most popular condition of Reicher's (1969) study, in which subjects were cued about both the alternative letters and the target position after the presentation of the display. With this forced choice recognition paradigm, the WLP has always been obtained (Johnston, 1978; Johnston \& McClelland, 1973; McClelland, 1976; McClelland \& Johnston, 1977; Reicher, 1969; Thompson \& Massaro, 1973, Experiment 1; Wheeler, 1970).

In a second condition, Reicher (1969) used the same procedure except that subjects were verbally precued before each trial about what the alternatives would be but not about the position the target would occupy in the display. With prior knowledge of the alternatives, overall performance was worse than with the no-precue procedure but the magnitude of the WLP remained unchanged. However, most of the studies using prior knowledge of the alternatives failed to show a WLP (Bjork \& Estes, 1973; Estes, 1975; Estes, Bjork, \& Skaar, 1974; Massaro, 1973, Experiment 1; Thompson \& Massaro, 1973, Experiment 2). Apart from Reicher (1969), the only study to show a WLP with the precue procedure was that of Carr, Lehmkuhle, Kottas, AstorStetson, and Arnold (1976). Several procedural differences can be responsible for the discrepancy between the results obtained with the precue procedure. Assumptions about the determinants of either a WLP or no WLP with prior knowledge of the alternatives 
will be discussed together with the results of the present study.

\section{EXPERIMENT 1}

Experiment 1 was designed as a partial replication of Reicher's (1969) study, allowing for a comparison between forced choice performance for letters embedded in words and letters presented alone with a no-precue and a letter-precue procedure. There are four main differences between Reicher's study and the present one: (1) Blocked presentations of word and letter contexts were used rather than random sequences of letters, words, and nonwords. (2) The cuing procedure, which was a within-subject variable in the previous study, was treated as a betweensubjects variable in the present one. (3) The subjects were tested for only 1 session instead of 14. (4) French words were used rather than English ones.

A second aim of the first experiment was to know whether the WLP would be influenced by the fact that the word target or distractor letter was either pronounced or unpronounced. French words probably contain more unpronounced letters than English ones. A letter may be unpronounced either because it is part of a multiletter grapheme generally denoting a vowel sound (e.g., ON, EU, Al. . .) or for morphological and etymological reasons (e.g., the last $T$ in ETAT or the D in PIED). The latter also includes the plural marks that are unpronounced, but they never occur in the present material, which contained only singular common nouns.

\section{Method}

Subjects. Forty-eight subjects from the Universite Ljbre de Bruxelles served as volunteer subjects for the $45-\mathrm{min}$ session required by the experiment. They were subdivided into two groups of 24 subjects each. One group of subjects was assigned to the no-precue condition and the other group to the letter-precue condition. All subjects were native speakers of French.

Apparatus and Stimuli. Stimuli were presented in a Scientific Prototype two-channel tachistoscope. Press-on black letters (Decadry No. 4) were used to compose the stimuli in the center of $4 \times 5$ in. white cards. The characters were uppercase letters subtending a visual angle of $.39^{\circ}$, both in width and in height, at a viewing distance of $87 \mathrm{~cm}$. With an intercharacter space of $.20^{\circ}$, a four-letter word subtended a visual angle of $2.17^{\circ}$ in width.

A pre- and postexposure pattern mask, similar to the one used by Johnston and McClelland (1973), was continuously visible except for the stimulus exposure duration. It consisted of curved intersecting continuous lines, about the same thickness as the letter strokes, included into a rectangular array subtending $3.48^{\circ}$ in width and $1.31^{\circ}$ in height. A red dot occupying the center of the masking pattern provided a fixation point.

One hundred and twenty-eight four-letter, mono- and bisyllabic French common nouns were selected in order to make 64 pairs of words whose members differed by only one letter. One member of each pair contained the target letter and the other member contained the distractor (e.g., ROBE-ROSE). Pairs of words were chosen in order to satisfy two different requirements. First, the target letter had to occupy each of the four possible positions equally often. Second, the target letter or the distractor was either pronounced $(P)$ with its usual value in French or unpronounced (UP). Due to the constraints of French vocabulary, the four types of pairs, P-P, P-UP, UP-P, and UP-UP' (the first abbreviation refers to the target and the second to the distractor) were unevenly represented. There were 40 P.P pairs: $12,10,10$, and 8 pairs, respectively, for the first, second, third, and fourth target position. Each of the other types of pairs was represented by 8 tokens, 2 per target position except for the UP-UP first target position category, which was empty, and for the UP-UP fourth target position, which contained 4 tokens instead of 2. As a consequence of the above requirements, some rather unfamiliar words were included in the list. Four words were unknown or barely known by a substantial proportion of the subjects.

Two blocks of 32 trials, each comprising a random sequence of half the target members from each of the 15 categories defined above (four positions by four pronunciation types less one), were constructed. Corresponding letter blocks were obtained by removing the three nontarget letters from each word, leaving the target letter in its corresponding position and filling the three empty positions with small plus signs subtending $.13^{\circ}$ of visual angle on the stimulus card. Only minimal lateral masking is expected from these signs, since they are three times smaller than the letters.

In addition, 20 pairs of words, different from the ones described above, were used to make one block of words and one block of letters to be used in practice trials.

The forced choice alternatives were displayed on the successive pages of small booklets. Each page of a booklet contained a trial number and the two alternatives, typewritten side by side in uppercase characters. The alternatives consisted of the presented word or letter and its associated distractor. The correct response occupied randomly the left or the right position equally often. For letter forced choices, the position occupied by the target in the visual field was signaled by three plus signs filling the nontarget positions.

Procedure. The subjects were individually tested by two experimenters. The second experimenter was needed to refill the cardholders without losing time. The forced choice task was explained to the subject at the beginning of the session. The necessity of having the fixation dot in clear focus before initiating a trial and of giving a response on each trial, guessing if necessary, was stressed.

In the no-precue condition, a trial started when the subject looked at the masking field with its centrally located red fixation dot. Following a verbal ready signal consisting of the trial number, the subject pressed a Morse key when he felt ready. This caused the immediate extinction of the masking field and the illumination of the stimulus for an individually predetermined exposure duration. The reappearance of the masking field, immediately after stimulus termination, also constituted a signal for the subject to look for the forced choice by turning the page of his booklet. The subject gave his response verbally by saying the letter or the word (depending on the block of trials) he thought was the stimulus. No information concerning the correctness of the response was provided.

In the letter-precue condition, the sequence of events comprising a trial was the same as in the no-precue condition, except that subjects were verbally told the identity of the letter alternatives after the trial number. The target was randomly spelled out as the first or the second letter equally often. No information was provided about the position in the visual field where the choice would take place. For letter trials, the subjects would have been able to give the forced choice response immediately after stimulus presentation without consulting their booklets. They were urged not to do so and to look into their booklets in order to take advantage of the visual cues before giving their responses.

A session began with a practice phase, during which the stimulus duration was modified on each trial following a staircase 
method and yielding roughly $75 \%$ correct responses. Since subjects generally improve rapidly in early practice with tachistoscopic exposures and since only 40 trials were used to determine the exposure duration to be used in the main part of the experiment, some precautions had to be taken to avoid a ceiling effect. In view of that possibility, for each subject, the staircase method was first applied to a block of 20 words, presumably the easiest context, and then to a block of 20 letters. Then a single exposure duration, to be used in the main part of the experiment, was obtained either by subtracting $5 \mathrm{msec}$ from the mean of the word and letter exposure durations when the letter exposure duration was the largest or by subtracting $5 \mathrm{msec}$ from the letter exposure duration when it was the smallest of the two values. Both groups of subjects were tested with the no-precue procedure during the practice phase.

The main part of the experiment consisted of four blocks of trials, two blocks of 32 words and two blocks of 32 letters. Letter and word blocks were presented in alternating order, half the subjects beginning with a letter block and the other half with the word block. The subjects were always told the context type (letter or word) before a block.

The single-exposure duration determined during the practice phase was used throughout the experimental phase, provided that the percentage of correct responses for both the first blocks of trials (one block of words and one block of letters) was between $62.5 \%$ and $87.5 \%$. If one of the percentage of correct responses from one of the first two blocks was greater than or equal to $87.5 \%, 10 \mathrm{msec}$ were subtracted from the exposure duration and this new value was used for the last two blocks of trials. a $10-\mathrm{msec}$ increase in exposure duration in case one of the percentages of correct responses for the two first blocks was less than or equal $1062.5 \%$ was also programmed, but it never occurred.

\section{Results}

For each subject, the percentage of correct responses was computed as a function of stimulus type (word or letter) for each level of the pronunciation factor. Table 1 shows the percent correct across subjects in the no-precue and the letter-precue conditions. As can be seen in Table 1, the overall level of performance is better in the letter-precue condition than in the no-precue condition ( $79 \%$ vs. $70 \%$ of correct responses). A longer mean exposure duration in the letter-precue condition ( $54 \mathrm{msec}$ ) than in the no-precue condition $(46 \mathrm{msec}$ ) is probably responsible for the difference in the overall level of performance. This, together with the fact that indi-

Table 1

Mean Percent of Correct Responses in Experiment 1

\begin{tabular}{lrrrrr} 
& P-P & P-UP & UP-P & UP-UP & Mean \\
\hline & \multicolumn{5}{c}{ No Precue } \\
Word & 75 & 76 & 72 & 72 & 74 \\
Letter & 67 & 65 & 66 & 65 & 66 \\
Difference & 8 & 11 & 6 & 7 & 8 \\
& \multicolumn{5}{c}{ Letter Precue } \\
Word & 83 & 80 & 79 & 78 & 80 \\
Letter & 80 & 73 & 77 & 82 & 78 \\
Difference & 3 & 7 & 2 & -4 & 2 \\
\hline
\end{tabular}

Note-P stands for pronounced and UP stands for unpronounced. The first designation refers to the target and the second refers to the distractor. vidually predetermined exposure durations were used in each group, precludes a detailed comparison of the performances observed in the no-precue and letterprecue conditions.

A two-way analysis of variance, with stimulus type and pronunciation factor as within-subject factors, was applied to the data of the no-precue condition. The stimulus type effect was significant $[F(1,23)=$ 8.33, $\mathrm{p}<.01$ ], showing that letters embedded in words are better recognized than letters presented alone. Neither the pronunciation effect nor its interaction with the stimulus type reached significance [both $\operatorname{Fs}(3,69)<1.0$ ]. A similar analysis of variance was applied to the letter-precue data. None of the effects, stimulus type, pronunciation, or their interaction, reached significance.

\section{Discussion}

The results of the no-precue condition replicated the word superiority effect reported by Reicher (1969) and others. The partition of the data as a function of whether the target or the distractor letter was either pronounced or unpronounced when embedded in a word gave no clue to the understanding of the WLP, since this factor was not significant and did not interact with stimulus type.

In the letter-precue condition, no WLP was observed, which contradicted the effect reported by Reicher (1969) in a similar condition. Unfortunately, the use of separate groups of individually adjusted subjects, which resulted in rather different mean exposure durations in the no-precue and the letterprecue conditions, precluded knowing the way the WLP disappeared (e.g., does it result from an increase in performance for single letter, a decrease in performance for words, or both?). In the absence of that information, one cannot speculate much about the discordance between Reicher's results and the present ones. This question was addressed in Experiment 2.

\section{EXPERIMENT 2}

Experiment 2 was designed to allow a direct comparison between performances in the no-precue and letter-precue conditions. Both procedures were passed by the same subjects on alternating trials of each block of words and letters.

\section{Method}

Subjects. Twenty-four students from the Université Libre de Bruxelles served as volunteer, paid subjects for a 45 -min session. They were native speakers of French. None of the subjects had participated in Experiment 1.

Apparatus and Stimuli. The apparatus and stimuli were the same as those in Experiment 1.

Procedure. The procedure was very similar to that used in Experiment 1. No precue was given during the practice phase of 
the experiment. During the main part of the experiment, the subjects were given no precue or a letter precue on alternating trials of each block. Half the subjects were precued on the odd trials of each block, and the other half were precued on the even trials of each block.

\section{Results}

Each subject's raw score was converted into a percentage of correct responses for both stimulus type (word and letter) and trial type (no precue and letter precue). The percent correct averaged across subjects appears in Figure 1. A two-way analysis of variance, with stimulus type and trial type as within-subject factors, was carried out on these data. The stimulus type effect was not significant $[F(1,23)=1.31$, $\mathrm{p}>$.10], and nor was the trial type $[\mathrm{F}(1,23)<1.0]$, but their interaction was significant $[F(1,23)=8.61$, $\mathrm{p}<.011$. Post hoc Scheffé comparisons showed that the only significant differences were between word and letter for the no-precue trials $(70 \%$ vs. $64 \%)$ and between the no-precue and letter-precue trials for words $(70 \%$ vs. $63 \%)$. Neither the small increase in letter performance for the letter-precue trials relative to the no-precue trials ( $66 \%$ vs. $64 \%$ ) nor the letter advantage over word for the letter-precue trials $(66 \%$ vs. $63 \%$ ) was significant.

The observed results are in good agreement with the subjects' introspective reports. Most of the subjects felt that precuing was disturbing with the word

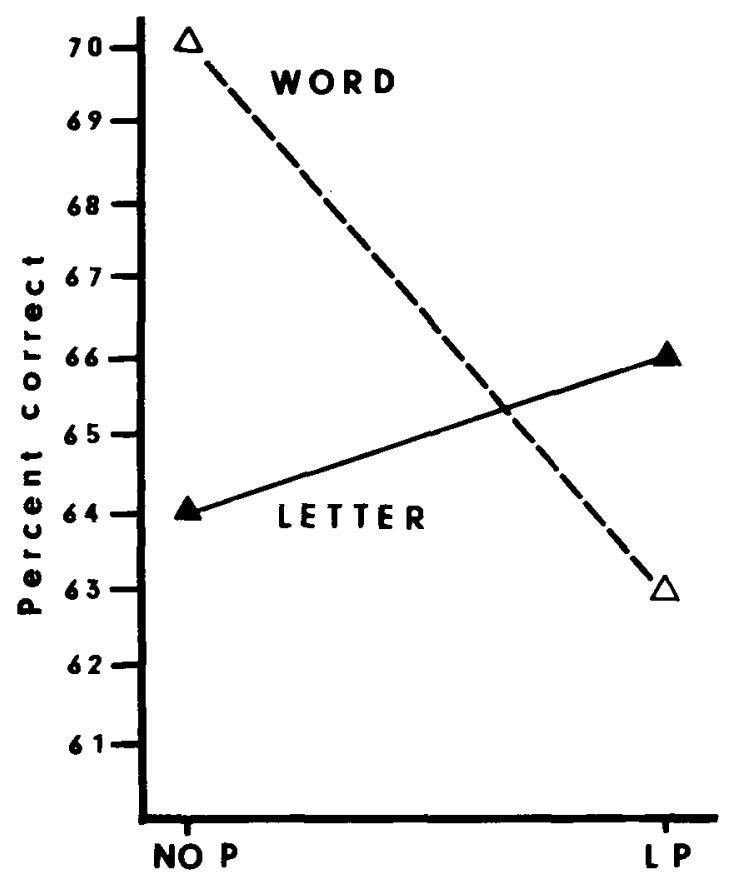

TRIAL TYPE

Figure 1. Mean percent of correct responses for letters in words (dotted line) and single letters (solid line) as a function of trial type (NO P: no precue; LP: letter precue) in Experiment 2. context, whereas precuing was felt as useless or helpful with the single-letter context.

\section{Discussion}

Experiments 1 and 2 show a WLP that occurred only with the no-precue procedure, but disappeared with the letter-precue procedure. The striking result of Experiment 2 is that the WLP suppression contingent upon precuing resulted from a decrease in performance for letters embedded in words rather than from an increase in performance for isolated letters. The only study in the literature that offers a comparison between a precue-postcue and a postcue procedure was that of Reicher (1969). In Reicher's study, both letter and word performance deteriorated by about the same amount in the letter-precue condition compared to the no-precue condition, leaving the WLP unchanged. In the present study, only word performance deteriorated, whereas no deterioration, or even a small but nonsignificant increase, in the letter performance was observed. That precuing impairs performance is rather unusual and requires further comment. My contention is that the way precuing affects performance is completely different for single-letter perception and for perception of letters embedded in words.

It should be remembered that the presence of a backward pattern mask is a necessary condition for observing a word superiority effect with the forced choice postcue procedure. When the stimulus is followed by a blank or a dark field rather than by a pattern mask, no WLP is observed (Johnston \& McClelland, 1973; Juola, Leavitt, \& Choe, 1974). Pattern masking is also of critical importance for observing a detrimental effect of precuing on singleletter perception. The latter was demonstrated by Smith, Haviland, Reder, Brownell, and Adams (1976), who first observed that the disruptive effect of precuing which occurs with a pattern mask gives place to a more expected facilitation effect when a blank field follows the target letter. They further showed the dependance of the disruptive effect upon the kind of pattern mask used, being stronger the more the mask features resemble the stimulus features. This latter finding could probably account for the discrepancy between the precue disruption effect on letter perception observed by Reicher (1969) and Smith, Haviland, Reder, Brownell, \& Adams (1976) and the absence of such disruption in the present experiment. The previous studies used a mask consisting of superposed Xs and Os, whose features are probably more similar to the target letter than the curved lines used in the present study.

It is fair to say that the effect of precuing on the perception of letters embedded in words is less dependent upon masking characteristics than perception of 
isolated letters. This assumption follows from the fact that the interaction between the mask and the target letter presumably arises immediately on a singleletter presentation, since the position in the visual field where information should be extracted is probably immediately detected. This is not the case for a letter embedded in a word, because the position in the visual field where the forced choice would take place is not readily accessible. Empirical evidences favoring this assumption can also be found in the work of Bjork and Estes (1973) and Estes et al. (1974), who showed that precued single-letter perception is more affected by the pre- and postmask characteristics than perception of letters embedded in words or nonsense strings. So what causes the precuing disruptive effect on letters embedded in words observed in Reicher's (1969) study and in the present Experiment 2? A tentative answer would be that the way subjects apprehend words is probably different under the two conditions. With prior knowledge of the alternatives, subjects would not attend to a word as a whole, but rather would be more analytical in order to find which position contained a plausible candidate for the precued forced choice. The reasoning is similar to the one proposed by Johnston and McClelland (1974) to explain why, for letters embedded in words, an instruction to fixate the target location decreases performance relative to a condition where the word is considered as a whole.

In summary, the advantage for a letter to be part of a word is critically dependent upon the subject's strategy. It occurs only when subjects decide to consider the word as a whole. Among the variables tending to keep subjects from using this strategy are: position precuing (Johnston \& McClelland, 1974) or letter alternatives precuing (e.g., present study), or both (Massaro, 1973; Thompson \& Massaro, 1973, see below). On the other hand, precuing on isolated letter perception would result in different effects, ranging from an enhancement when no mask follows the target to an impairment of performance when the mask features resemble the target features. If one is prepared to accept the above reasoning, it should be ironically stressed that the constant WLP observed by Reicher (1969) should be called a "word advantage effect" in the no-precue condition and a "letter deterioration effect" in the letter-precue condition.

\section{GENERAL DISCUSSION}

Experiments 1 and 2 have shown the WLP to be suppressed by precuing for the alternatives. This is in good agreement with most of the studies that have provided prior knowledge of the forced choice (Bjork \& Estes, 1973; Estes, 1975; Estes et al., 1974; Massaro, 1973; Thompson \& Massaro, 1973) but in contradiction with the already discussed WLP maintenance found by Reicher (1969) but also by Carr et al. (1976). Unfortunately, no studies other than Reicher's (1969) and the present Experiment 2 provide the opportunity to compare performance in a precue-postcue and a postcue paradigm. However, since the pattern mask used by Carr et al. (1976) was similar to the one used in the present study, one can speculate that no letter deterioration effect can account for the advantage of letters embedded in words over single letters. If so, Carr et al.'s (1976) results would indicate a genuine maintenance of the word processing mode with precuing.

Carr et al. (1976) used the same restricted set of alternatives, consisting of the letters, C, G, P, and $R$, as Massaro (1973) and Thompson and Massaro (1973). They first argue that Massaro's (1973) and Thompson and Massaro's (1973) failure to find a WLP resulted from their subjects' being precued about both the alternatives and the position the target would occupy, since the target was either an isolated letter presented at fixation or the central letter of a three-letter word (ACE, AGE, APE, or ARE). This is a sound assumption, since focusing on the central position presumably suppressed the advantage of considering the word as a whole (Johnston \& McClelland, 1974). The additional letter advantage observed in these experiments could be explained by the absence of lateral masking affecting letters presented alone relative to letters embedded in words (Thompson \& Massaro, 1973). Carr et al. (1976) further argue that the WLP they observed resulted from their subjects' being precued only about the alternatives, but not about the position the target would occupy in the visual field. But this is a spurious argument, since it does not explain why other studies using a restricted set of alternatives ( $L$ or $R$ ) and no information about position failed to show a WLP (Bjork \& Estes, 1973; Estes, 1975; Estes et al., 1974). So, what causes the WLP observed by Carr et al. (1976)? One possible answer comes from a study by Purcell, Stanovich, and Spector (1978).

With the same restricted set of alternatives as Massaro (1973) and with precued positions, Purcell et al. (1978) reported a WAE for the comparison of the word stimuli ACE, AGE, APE, and ARE with the nonsense strings VCH, VGH, VPH, and VRH, whereas Massaro (1973, Experiment 2) failed to find any difference between both contexts. The important difference between these two studies lies in the visual angle subtended by the three-letter strings. Purcell et al. (1978) used a small visual angle of $.53^{\circ}$, whereas Massaro (1973) used a large visual angle of $3.33^{\circ}$. This is an important result, since it suggests that even when subjects presumably focus their attention on one position, they are unable not to benefit from the word context provided that the visual angle subtended by the word is small. Purcell et al. (1978) further 
argue for their visual angle hypothesis with the results of their third experiment, which showed no more WAE when stimuli subtended $2.11^{\circ}$ of visual angle. Unfortunately, they did not use letters big enough to allow for a normal spacing of the characters composing the words or nonwords. As a consequence, the increase in the visual angle subtended by the stimuli was confounded with a very unusual spacing of the letters. The space between characters was 2.9 times the letter width compared with half the letter width in the study of Massaro (1973).

The criticism of Purcell et al. (1978) study does not reduce the potential importance of the visual angle and/or spacing of the characters in the determination of the WLP and the WAE. This is further confirmed by the fact that Carr et al.'s (1976) WLP was obtained with words subtending $1.0^{\circ}$ of visual angle, whereas Estes and his collaborators (Bjork \& Estes, 1973; Estes, 1975; Estes et al., 1974) and Massaro (1973, Experiment 1), with words subtending $4.5^{\circ}$ and $3.33^{\circ}$, respectively, observed no WLP. In all those studies, the spacing of the characters forming words was fairly normal. Silverman's (1976) finding that in a two-choice speeded classification task, with both alternatives and position known in advance, letters composing words behave like integral, rather than separable, dimensions (following Garner \& Felfoldy, 1970) could also be a consequence of the small visual angle $\left(.78^{\circ}\right)$ he used for his three-letter stimuli. The only discordant result was the absence of WLP in the second experiment carried out by Thompson and Massaro (1973) using three-letter words normally typewritten and probably subtending about $.50^{\circ}$ of visual angle.

Finally, the visual angle hypothesis cannot account for the already discussed discrepancy between the WLP observed by Reicher (1969) and the absence of such an effect in the present experiments. Both studies used normal spacing of the characters forming words and very similar visual angles: namely, less than $2^{\circ}$ in Reicher's research and $2.17^{\circ}$ in the present one.

\section{REFERENCES}

BJoRK, E. L., \& Estes, W. K. Letter identification in relation to linguistic context and masking conditions. Memory \& Cognition, $1973,3,217-223$.
Carr, T. H., Lehmkuhle, S. W., Kottas, B., Astor-Stetson, E. C., \& ARNolD, D. Target position and practice in the identification of letters in varying contexts: A word superiority effect. Perception \& Psychophysics, 1976, 19, 412-416.

Estes, W. K. The locus of inferential and perceptual processes in letter identification. Journal of Experimental Psychology: General, 1975, 104, 122-145.

Estes, W. K., Buork, E. L., \& SkaAr, E. Detection of single letters and letters in words with changing vs. unchanging mask characters. Bulletin of the Psychonomic Society, 1974, 3, 201-203.

GARNER, W. R., \& Felfoldy, G. L. Integrality of stimulus dimensions in various types of information processing. Cognitive Psychology, 1970, 1, 225-241.

Johnston, J. C. A test of the sophisticated guessing theory of word perception. Cognitive Psychology, 1978, 10, 123-153.

Johnston, J. C., \& McClelland, J. L. Visual factors in word perception. Perception \& Psychophysics, 1973, 14, 365-370.

Johnston, J. C., \& McClelland, J. L. Perception of letters in words: Seek not and ye shall find. Science, 1974, 184, 1192-1194.

Juola, J. F., LeavitT, D. D., \& ChoE, C. S. Letter identification in word, nonword, and single-letter displays. Bulletin of the Psychonomic Society, 1974, 4, 278-280.

MASSARO, D. W. Perception of letters, words, and nonwords. Journal of Experimental Psychology, 1973, 100, 349-353.

MCClelland, J. L. Preliminary letter identification in the perception of words and nonwords. Journal of Experimental Psychology: Human Perception and Performance, 1976, 2, 80-91.

McClelland, J. L., \& Johnston, J. C. The role of familiar units in perception of words and nonwords. Perception \& Psychophysics, 1977, 22, 249-261.

Purcell, D. G., Stanovich, K. E., \& Spector, A. Visual angle and the word superiority effect. Memory \& Cognition, 1978, 6, 3-8.

Reicher, G. M. Perceptual recognition as a function of meaningfulness of stimulus material. Journal of Experimental Psychology, 1969, 81, 275-280.

Silverman, W. P. Can "words" be processed as integrated units? Perception \& Psychophysics, 1976, 20, 143-152.

Smith, E. E., Haviland, S. E., Reder, L. M., Brownell, H., \& Adams, N. When preparation fails: Disruptive effect of prior information on perceptual recognition. Journal of Experimental Psychology: Human Perception and Performance, 1976, 2, 151-161.

Thompson, M. C., \& Massaro, D. W. Visual information redundancy in reading. Journal of Experimental Psychology, 1973, 98, 49-54.

Wheeler, D. D. Processes in word recognition. Cognitive Psychology, 1970, 1, 59-85.

\section{NOTE}

1. Although both members of a NP-NP pair could potentially have been homophones, it actually never occurred. Examples of NP-NP pairs are: TOUX-TAUX, JOIE-JOUE, PIED-PIEU.

(Received for publication August 28, 1978; revision accepted January 20, 1979.) 